\title{
GTP cyclohydrolase I deficiency
}

INSERM

\section{Source}

INSERM. (1999). Orphanet: an online rare disease and orphan drug data base. GTP cyclohydrolase / deficiency. ORPHA:2102

GT P-cyclohydrolase I deficiency, an autosomal recessive genetic disorder, is one of the causes of malignant hyperphenylalaninemia due to tetrahydrobiopterin deficiency. Not only does tetrahydrobiopterin deficiency cause hyperphenylalaninemia, it is also responsible for defective neurotransmission of monoamines because of malfunctioning tyrosine and tryptophan hydroxylases, both tetrahydrobiopterin-dependent hydroxylases. 